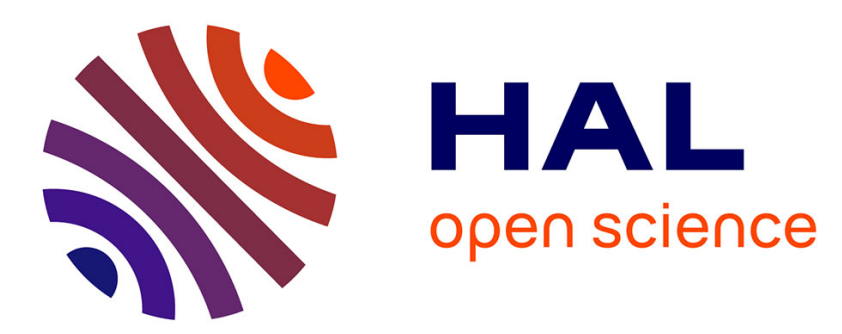

\title{
Atoms and bonds in molecules and chemical explanations
}

Mauro Causá, Andreas Savin, Bernard Silvi

\section{To cite this version:}

Mauro Causá, Andreas Savin, Bernard Silvi. Atoms and bonds in molecules and chemical explanations. Foundations of Chemistry, 2014, 16 (1), pp.3 - 26. 10.1007/s10698-013-9192-2 . hal-01112385

\section{HAL Id: hal-01112385 https://hal.sorbonne-universite.fr/hal-01112385}

Submitted on 2 Feb 2015

HAL is a multi-disciplinary open access archive for the deposit and dissemination of scientific research documents, whether they are published or not. The documents may come from teaching and research institutions in France or abroad, or from public or private research centers.
L'archive ouverte pluridisciplinaire HAL, est destinée au dépôt et à la diffusion de documents scientifiques de niveau recherche, publiés ou non, émanant des établissements d'enseignement et de recherche français ou étrangers, des laboratoires publics ou privés. 


\title{
Atoms and bonds in molecules and chemical explanations*
}

\author{
Mauro Causáł Andreas Savin ${ }^{\ddagger}$ and Bernard Silvi ${ }^{\S}$
}

\begin{abstract}
The concepts of atoms and bonds in molecules which appeared in chemistry during the XIX $^{\text {th }}$ century are unavoidable to explain the structure and the reactivity of the matter at a chemical level of understanding. Although they can be criticized from a strict reductionist point of view, because neither atoms nor bonds are observable in the sense of quantum mechanics, the topological and statistical interpretative approaches of quantum chemistry (QTAIM, ELF and MPD) provide consistent definitions which accommodate chemistry and quantum mechanics.
\end{abstract}

\section{About the explanation of the bonding in chemical systems.}

One of the aims of chemistry, as a science, is to study and explain the structure of the matter and its transformations. By explain it is meant that science has to tell how and why a given phenomenon occurs in given circumstances. Scientific explanation has been discussed by philosophers who proposed different accounts (for a review see (Strevens, 2006; Woodward, 2011)), for example, Hempel's deductive-nomological, or DN, account (Hempel \& Oppenheim, 1948), the unification account (Friedman, 1974; Kitcher, 1981), the causal account (Salmon, 1984) and the kairetic account (Strevens, 2004) which attempts to catch the advantages of the unification and causal accounts. In

\footnotetext{
*Dedicated to the memory of Professor Richard F. W. Bader

${ }^{\dagger}$ Dip. di Chimica, Universitá di Napoli Federico II, Via Cintia, 80126 Napoli, Italy

${ }^{\ddagger}$ Laboratoire de Chimie Théorique (UMR-CNRS 7616), Université Pierre et Marie Curie, 4 place Jussieu, 75252-Paris, France

§Laboratoire de Chimie Théorique (UMR-CNRS 7616), Université Pierre et Marie Curie, 4 place Jussieu, 75252-Paris, France
} 
brief, the DN account provides a scheme for any deterministic explanation of a particular event and consists in a deductive derivation of the occurrence of the event from a set of true propositions involving at least a scientific law or principle. The unification approach intends to derive the occurrence of the event using a theory that unifies many phenomena or the theory that unifies the phenomena better than any other. In the causal model the explanation will trace the causal processes and interactions leading to the event (i.e. the causal history), or at least a subset of these, as well as describing the processes and interactions that make up the event itself. Except for a dogmatic acceptation of the unification account, these different approaches leave a rather great freedom provided the explanation contains no false representation of reality. They do not invalidate the recourse to empirical laws, idealization or conjectures and enable to consider different levels of explanation. As pointed out by E. Scerri (Scerri, 2000)

If one believes only in fundamental explanations, this form of activity appears to be seriously mistaken. However, as chemists we are also aware of the need to operate on many levels and the fact that explanations can be genuinely levelspecific. Such approaches must be used very carefully. They should not degenerate into the introduction of ad hoc explanations that are invoked in the explanation of particular chemical facts but cannot be generalized to other situations.

In principle, explanations are not essentially communicative and exist independently of the intention of explaining anything to anyone. However, the availability of different levels of explanation is essential for the transmission of knowledge and therefore for the development of scientific ideas.

In the special issue of the Annals of the New York Academy of Sciences entitled "CHEMICAL EXPLANATION: Characteristics, Development, Autonomy" published in May 2003, G. del Re exemplified the difference between a chemical explanation and other explanations of facts. He considered the expected answers to the following question (Del Re, 2003):

Why are most glass bottles green? A technologist would respond by saying that their production cost is lower; a physicist would answer that their glass absorbs light selectively, so that the transmitted light has a different spectrum from that of sunlight; but a chemist would answer that it is because ordinary glass contains ferrous ions.

This example shows that several causal processes may be invoked to explain a fact. In the present case all answers are relevant and complementary since 
they partially address the question. This example insists on the cultural differences between scientific communities.

Chemical explanations of the structure of the matter and its transformations mostly rely upon a reductionist approach which describes the matter as an assembly of molecules or crystals themselves composed of elemental atoms. The mutual interaction of these elemental atoms, in other words the bonding, is ruled by the location of the involved elements in the periodic table which determines their "atom in molecules" properties such as electronegativity, valence, ionic and covalent radii. This description can be viewed as a synthesis of the early mechanistic and substantialist conception of the matter. The electronic origin of the bonding is accounted for by very simple and efficient phenomenological models: the ionic and covalent bond models and the mesomery. Moreover, the Valence Shell Electron Pair Repulsion (VSEPR) and Ligand Close Packing (LCP) models (Gillespie \& Nyholm, 1957; Gillespie, 1972; Gillespie \& Robinson, 1996; Gillespie, 2000; Gillespie \& Popelier, 2001) state rules which explain the molecular geometry. Many chemical explanations belong to either the DN account or the the causal approach. For example the formation of an ionic bond can be deduced from the electronegativities of the involved elemental atoms and from the electronegativity equalization principle which implies the exchange of an extensive quantity (here electrons) yielding opposite charge ions attracted by the Coulomb electrostatic laws. Reaction mechanisms depicted by curly arrows can be viewed as causal stories.

Rather than atoms, the reduction of chemistry to physics is an example of the unification account in action. It considers interacting particles ruled by the laws of quantum mechanics which enable an almost complete description of the interaction between electron and nuclei and therefore the quantitative exact predictions of observables. It corresponds to a mechanistic working program anticipated by Dirac in 1929 (Dirac, 1929):

The underlying physical laws necessary for the mathematical theory of a large part of physics and the whole of chemistry are thus completely known, and the difficulty is only that the exact application of these laws leads to equations much too complicated to be soluble.

Although the predictive power of quantum mechanics is indisputable, its ability to provide explanations has been questioned by René Thom in Prédire n'est pas expliquer (Thom, 1993):

La mécanique quantique est incontestablement le scandale intellectuel du siècle! 
Comment entendez vous scandale?

C'est que la science a renoncé à l'intelligibilité du monde; elle y a réellement renoncé! C'est quelque chose qui s'impose et qui n'est pas intelligible. ${ }^{1}$

Thom's provocative remark echoes Niels Bohr's attitude reported by Karl R. Popper in the introductory comments of Quantum Theory and the Schism in Physics (Popper, 1992)

When he accepted quantum mechanics as the end of the road, it was partly in despair: only classical physics was understandable, was a description of reality. Quantum mechanics was not a description of reality. Such a description was impossible to achieve in the atomic region; apparently because no such reality existed: the understandable reality ended where classical physics ended.

and Popper's assessment from the 1982 preface of the same book:

Today, physics is in a crisis. Physical theory is unbelievably successful; it constantly produces new problems, and it solves the old ones as well as the new ones. And part of the present crisis the almost permanent revolution of its fundamental theories - is, in my opinion, a normal state of any mature science. But there is also another aspect of the present crisis: it is also a crisis of understanding.

The reservation of René Thom concerning the lack of intelligibility of quantum mechanics as well as Popper's crisis of understanding can be explained by the status of quantum systems as discussed by Heelan (Heelan, 2003):

An individual quantum object is intuitively given to an observer only by the actual isolated footprints it leaves in the perceptual world of the laboratory, the record of individual measurements. It is not just a conceptual object, nor is it an "embodied object in its own right. It is, however, physical and material because of the footprints it makes in the world. It seems then to exist and function ontologically prior to and i some way independently of the phenomenological constitution of classically scientific laboratory space-time.

\footnotetext{
${ }^{1}$ Quantum mechanics is undeniably the intellectual scandal of the century! What do you mean by scandal?

I mean Science has renounced intelligibility, It has really renounced! That's something which asserts itself and which is not understandable.
} 
The interpretation of approximate wavefunctions is the most popular approach used by quantum chemist (and others) to build up explanations of the structure and reactivity of chemical species. It had been encouraged by Dirac who wrote in the last sentence of his 1929 paper "Quantum mechanics of Many-Electron Systems" (Dirac, 1929):

It therefore becomes desirable that approximate practical methods of applying quantum mechanics should be developed, which can lead to an explanation of the main features of complex atomic systems without too much computation.

This prescription has been anticipated two years before Dirac's paper by the calculations of the dihydrogen molecule of Heitler and London (Heitler \& London, 1927) on the one hand and of Condon (Condon, 1927) on the other hand. ${ }^{2}$ Heitler and London's paper was immediately recognized as a milestone in the history of chemistry. Here was found the mathematical dynamic formulation of Lewis' covalent bond, the energy of the electron pair bond being given as a resonance energy due to the interchange of two electrons. As pointed out by Pauling (Pauling, 1954):

Condon's treatment is the prototype of the molecular-orbital treatment that has been extensively applied in the discussion of aromatic and conjugated molecules, and Heitler and London's treatment is the prototype of the valence-bond method.

These two methods constitute the backbone of the theory of chemical bonding (Hoffmann et al., 2003):

Quantum mechanics has provided chemistry with two general theories, valence bond (VB) and molecular orbital (MO) theory. The two theories were developed at about the same time, but quickly diverged into rival schools that have competed, sometimes fervently, on charting the mental map and epistemology of chemistry.

Though these methods have proved their efficiency in both predictive and interpretative purposes, they have a constitutive epistemological weakness because they mostly rely on the interpretation of the approximate wave function in terms of its atom related components rather than upon observable quantities. As pointed out by Coulson (Coulson, 1952):

\footnotetext{
${ }^{2}$ Condon's calculation uses the $\mathrm{H}_{2}^{+}$analytical result of Burrau(Burrau, 1927) to build the $\mathrm{H}_{2}$ approximate wavefunction. The MO method has been independently developed by Hund(Hund, 1926, 1928, 1932; Mulliken, 1928a,b; Lennard-Jones, 1929).
} 
This epistemological difficulty is mostly due to the weakness of interpretative methods that give a physical significance to quantities, such as molecular orbitals or valence bond structures, appearing as intermediates during the course of solution of the many-body Schrödinger equation.

In a second approach, no more than interpretative postulates is required and no approximation is considered in the principles. The key is then to import a mathematical method of analysis to perform the partition. Theories derived accordingly should (Aslangul et al., 1972) "provide the mathematical bridge between the chemical intuition and wave mechanics, which may be considered as a theoretical justification of the main chemical ideas." Several interpretative methods have been developed in this spirit: the loge theory (Daudel, 1953; Daudel et al., 1954, 1955; Aslangul et al., 1972, 1974), the quantum Theory of Atoms in Molecules (QTAIM) (Bader, 1964; Bader et al., 1966, 1971; Bader, 1975; Bader et al., 1979; Bader \& Nguyen-Dang, 1981; Bader, 1985, 1990, 1991; Bader et al., 1996a; Bader, 2005, 2007), the topological analysis of the electron localization function (Häussermann et al., 1994b; Silvi \& Savin, 1994; Savin et al., 1997; Savin, 2005; Silvi et al., 2005) and of the electron localizability indicator (Kohout et al., 2004, 2005; Wagner et al., 2007) as well as the determination of maximum probability domains (Cancès et al., 2004; Gallegos et al., 2005; Lopes et al., 2012) and the determination of the electron number probability distribution functions (Francisco et al., 2007; Martín Pendás et al., 2007; Martín Pendás et al., 2007; Martin Pendas et al., 2007). This route has been recently reexamined by Richard Bader (Bader, 2011) and by (Bader \& Matta, 2012) to justify the universality of the QTAIM approach. Richard Bader clearly rejects the chemical approach claiming (Bader, 2011)

Readers of this paper must be prepared to encounter the view that chemistry has been reduced to physics and that the existing language of chemistry stated in terms of models based on valence bond and molecular orbital theories and related notions such as electronegativity, resonance, Coulson's overlap integral, non-bonded and steric interactions as well as 'Pauli repulsions', is to be replaced in its entirety by physics.

A third approach, the conceptual DFT, (Parr et al., 1978; Parr \& Pearson, 1983; De Proft \& Geerlings, 2001; Geerlings et al., 2003) provides definitions of global (chemical potential/electronegativity, hardness, softness, electrophilicity) and local (Fukui functions, local hardness) reactivity related 
properties in terms of energy derivatives. This approach rationalizes chemical laws such as the electronegativity equalization or the hard soft acid base principle often used to explain bonding properties.

\section{The autonomy of chemistry}

Chemistry has both a scientific side (study of the matter and of its evolution) and a technological side (synthesis, applied analytical chemistry) which are intricate even in quantum chemistry. In the hierarchy of sciences, chemistry, is generally ranked after physics. As pointed out by van Brakel (van Brakel, 2003)

This prejudice goes back to Kant's view that science is "proper" to the extent that mathematics is applied within it. According to Kant, chemistry is rational (because it uses logical reasoning), though not a proper science, because it misses the basis of mathematics and the synthetic a priori chemistry is an uneigentliche Wissenschaft -an "improper" science.

Kant followed the evolution of chemistry considering Stahl's phlogistic theory as a scientific revolution before accepting Lavoisiers's views (Vasconi, 1999; van Brakel, 2006). Nevertheless, Kant writing at the end of the XVIII ${ }^{\text {th }}$ century considered the mathematics and chemistry of those days. During the XIX $^{\text {th }}$ century mathematical models have been developed in chemistry independently of any reductionist attempt, either implicitly such as in Dalton's law of multiple proportions or explicitly such as in the law of mass action or in kinetics.

Chemistry has known a considerable development along the XIX $^{\text {th }}$ during which a large number of the natural elements have been discovered as well as many fundamental chemical concepts have been introduced. The periodic law of Mendeleev remains a culminating achievement of this area. At the turn of the XIX ${ }^{\text {th }}$, the law of the definite proportions and the law of multiple proportions enabled the introduction of a consistent description of the matter through the definition of stoichiometry coefficients. These latter are integers for a large majority of chemical compounds (exceptions are the consequence of a random substitution in crystals and glasses yielding formulas such as $\mathrm{Zn}_{1-\mathrm{x}} \mathrm{Cd}_{\mathrm{x}} \mathrm{Cl}_{2}$ ) which implies a discontinuous description of the matter in terms of atoms. In the model of Dalton, atoms are small indivisible bodies surrounded by an envelope of caloric. (Dalton, 1808) The model was further improved by Laming who was aware of Faraday's electrochemical equivalent. Laming's hypotheses (Laming, 1845) replaces caloric by electricity: 
1. different sorts of atoms are naturally associated with unequal quantities of electricity

2. a mass of electrical matter, or electricity, may be regarded as composed of electrical atoms, just as a mass of ordinary matter contains ordinary atoms; and thus the sphere of electricity which surrounds an ordinary atom will consist of a number of electrical atoms arranged in concentric strata. The number of electrical atoms belonging to a given ordinary atom may be assumed to be such as to complete its external spherical stratum,or, on the contrary, it may be such as to leave that external spherical stratum more or less imperfect.

At the beginning of the $\mathrm{XX}^{\text {th }}$ century, a few years after Thomson's discovery of the electron, G. N. Lewis proposed in a memorandum dated March 28, 1902 (Lewis, 1916), his cubic atomic model in which the vertices are occupied or not by electrons according to the element's column in the periodic table. In this way, he established a direct link between electrons and the concept of valence which provides a foundation to Abegg's valence and countervalence law (Abegg, 1904). It is worth noting that these different atomic models have been conceived on the only basis of chemical arguments. Moreover, Lewis atom is closer to nowadays representations than Thomson's 1904 plumpudding model (Thomson, 1904).

The derivation of a model explaining the bonding was made by the same Lewis in the 1916 paper "The Atom and the Molecule" published by the American Chemical Society (Lewis, 1916). Lewis's approach is based on six postulates

1. In every atom is an essential kernel which remains unaltered in all ordinary chemical changes and which possesses an excess of positive charges corresponding in number to the ordinal number of the group in the periodic table to which the element belongs.

2. The atom is composed of the kernel and an outer atom or shell, which, in the case of the neutral atom, contains negative electrons equal in number to the excess of positive charges of the kernel, but the number of electrons in the shell may vary during chemical change between 0 and 8 .

3. The atom tends to hold an even number of electrons in the shell, and especially to hold eight electrons which are normally arranged symmetrically at the eight corners of a cube. 
4. Two atomic shells are mutually interpenetrable.

5. Electrons may ordinarily pass with readiness from one position in the outer shell to another. Nevertheless they are held in position by more or less rigid constraints, and these positions and the magnitude of the constraints are determined by the nature of the atom and of such other atoms as are combined with it.

6. Electric forces between particles which are very close together do not obey the simple law of inverse squares which holds at greater distances.

The third postulate is the consequence of a chemical fact: the stoichiometry of almost all chemical species implies that they have an even number of electrons, this fact is the chemical footprint of the fermionic nature of the electron. The importance of the electron pair was recognized by Lewis 6 years before the Stern and Gerlach experiment and 9 years before the theoretical introduction of the electron spin $^{3}$ (Uhlenbeck \& Goudsmit, 1925; Pauli, 1925; Uhlenbeck, 1926). As a consequence of the pair formation, electron occupying the vertices of a same edge are drawn together towards the middle of the edge. Therefore the group of 8 electrons is reorganized in 4 pairs arranged tetrahedrally. This model accounts for the characteristics of the carbon atoms as well as for the formation of triple bonds and for the free rotation around a single bond.

Lewis emphasized the concept of electron pair as the cornerstone of molecular structure and proposed to write the formulas of chemical compounds by using atomic symbols surrounded by a number of dots corresponding to the number of electrons in the atomic shell. In spite of its simplicity, Lewis's approach is remarkably efficient and therefore remains fundamental for basic chemical education. Although Lewis's model explains the structure of a majority of molecular species, it fails, for example, to account for the hexagonal structure of benzene or for the paramagnetism of dioxygen. The attempts of Huggins to understand benzene by a single Lewis structure yielded chimerical representations (Huggins, 1922) whereas the concept of mesomery, pioneered by Ingold, (Ingold, 1922, 1933) which considers a weighted superposition of structures has been very successful with this respect and therefore constitutes an important complement to Lewis's model. In order to be able to treat dioxygen, Linnett modified the original Lewis model by splitting the initial octet into two sets of four electrons, one having one spin quantum number and the other the opposite spin (Linnett, 1961, 1964).

\footnotetext{
${ }^{3}$ Lewis's sixth postulate which seems in contradiction with quantum mechanics can be considered as an anticipation of Pauli's exclusion principle (Pauli, 1925)
} 
Sidgwick and Powell (Sidgwick \& Powell, 1940) remarked that the spatial arrangement of ligands around a central atom conforms to a quite limited number of types. They related this grouping to the size of the shared valency groups, the number of involved shared electrons together with that of the unshared groups. This description implicitly introduces a spatial extension of the bonding and non bonding pairs which is more consistent with the physical reality than the fixed pairs of Lewis. In the Sidgwick and Powell's model both shared and unshared groups have the same size which is uniquely determined by the type of spatial arrangement considered. This model was considerably improved by Gillespie and Nyholm (Gillespie \& Nyholm, 1957) who assumed that the arrangement of the pairs around a given center aroused from their mutual repulsion. The repulsion depends upon the type of pairs involved: a lone pair repels other electron pairs more than a bonding pair, a double bond repels other bonds and the repulsion depends on the electronegativity. In revised account of the Valence Shell Electron Pair Repulsion (VSEPR), electron pair domains are considered rather than the point on a sphere representation of the earlier version. Electronic pair domains are defined as a charge cloud which occupies a given region of space and excludes other pairs from this region as a consequence of the Pauli exclusion principles. This electron pair domain version of VSEPR emphasizes the shape and size of the domains rather than the magnitude of their mutual repulsion. In addition to bond and lone pair domains, Gillespie considers single electron domains which are expected to be smaller than an electron pair domain (Gillespie \& Robinson, 1996). The VSEPR model is very successful in predicting qualitatively the shape of molecules. It enables to understand many features of the molecular geometry in a qualitative fashion. Implicitly, the motion of nuclei is not considered.

Both Lewis's and VSEPR models provide rather simple complementary explanations of molecular structure, a reason which explains their wide use in chemical education. The formation of individualized electron pairs of different types is the keystone of these models. It is not an experimental fact and it is questionable from a strict theoretical point of view. Most of the justification rely on the Pauli's principle and implicitly on the orbital approximation, for example Salem considers (Salem, 1978):

Two electrons-hut no more than two-can "form" or "enter" or "occupy," as it were, the same wave. For this to occur, there must be a special matching. Electrons have an intrinsic, intimate, characteristic property. For two electrons to enter the same wave, they must have opposite characteristics. Hence, without pushing the analogy too far, it is legitimate to speak of an electron couple. 
The properties associated to pairs, such as bonding or not bonding character, location, size of their domain, are even more hypothetical and it appears necessary to revisit their definitions.

\section{Linking chemical concepts and quantum me- chanics}

The concepts of chemistry often lack of scientificity or have not enough precise or inconsistent definitions. For example, although the concept of chemical bond is at the heart of chemistry Pauling's definition (Pauling, 1948) adopted in the IUPAC gold book (McNaught \& Wilkinson, 1997)

There is a chemical bond between two atoms or groups of atoms in the case that the forces acting between them are such as to lead to the formation of an aggregate with sufficient stability to make it convenient for the chemist to consider it as an independent 'molecular species'.

introduces forces acting on nuclei (rather than atoms) which implicitly depend on the choice of a force field model (valence force field, Urey-Bradley force field, ... ), and should be therefore determined by an arbitrary decomposition of the resultant of the force vectors on each centre which is expected to vanish at the equilibrium geometries. Moreover, it recourses to the decision of an ideal chemist. In spite of a precise definition, the concept of chemical bond is supported by a multiplicity of criteria derived from experimental structural and thermodynamical measures as well as theoretical ones. As pointed out by Alvarez et al (Alvarez et al., 2009)

If one allows oneself to use a multiplicity of criteria, bonds may exist by one measure, not by another. This is not a reason to wring our hands, nor complain how unscientific chemistry is (or how obstinate chemists are). chemistry has done more than well in creating a universe of structure and function on the molecular level with just this "imperfectly defined" concept of a chemical bond. Or maybe it has done so well precisely because the concept is flexible and fuzzy.

This makes difficult the construction of bridges between chemistry and quantum mechanics and leads to ask the following question: are chemical and physical approaches mutually exclusive or complementary? It seems therefore interesting to consider the hypothetical features of the Lewis's and VSEPR 
models in the context of exact quantum mechanics. By exact quantum mechanics we do not mean exact wave functions but that we will not consider mathematical intermediates due to the approximation introduced in the calculus of the wavefunctions. We adopt here the point of view of the statistical interpretation of quantum mechanics which emphasizes the importance of electron densities further put forward by the DFT formulation.

\subsection{Quantum mechanical background}

This technical subsection presents the derivation of the density of probability functions and related objects used to build links between phenomenological chemical models and quantum mechanics. Assuming the Born-Oppenheimer separation, the electronic wavefunction is a function of $4 N$ variables: each electron, labelled by $i$, is described by the three components of its position vectors $\mathbf{r}_{i}$ and by its spin coordinates $\boldsymbol{\sigma}_{i}$. In order to simplify the notation $\mathbf{r}_{i}$ and $\boldsymbol{\sigma}_{i}$ are gathered in a four component (space+spin) vector $\boldsymbol{\xi}_{i}$. According to the statistical interpretation of quantum mechanics the product

$$
P_{N}\left(\boldsymbol{\xi}_{1}, \boldsymbol{\xi}_{2}, \ldots, \boldsymbol{\xi}_{N}\right)=\Psi\left(\boldsymbol{\xi}, \boldsymbol{\xi}_{2}, \ldots, \boldsymbol{\xi}_{N}\right) \Psi^{*}\left(\boldsymbol{\xi}, \boldsymbol{\xi}_{2}, \ldots, \boldsymbol{\xi}_{N}\right)
$$

represents the probability of finding the electrons labelled $1,2, \ldots, N$ in the volume elements $d \boldsymbol{\tau}_{1}, d \boldsymbol{\tau}_{2}, \ldots, d \boldsymbol{\tau}_{N}$ located at points $\mathbf{r}_{1}, \mathbf{r}_{2}, \ldots, \mathbf{r}_{N}$ with the spin coordinates $\boldsymbol{\sigma}_{1}, \boldsymbol{\sigma}_{2}, \ldots, \boldsymbol{\sigma}_{N}$. The indiscernability of the electrons implies that the probability of finding any $N$ electrons at these positions is:

$$
\Gamma^{(N)}\left(\boldsymbol{\xi}_{1}, \boldsymbol{\xi}_{2}, \ldots, \boldsymbol{\xi}_{N}\right)=N ! P_{N}\left(\boldsymbol{\xi}_{1}, \boldsymbol{\xi}_{2}, \ldots, \boldsymbol{\xi}_{N}\right)
$$

The probability of finding $k$ electrons with the ordered space and spin coordinates specified by the list of variables $\left.\boldsymbol{\xi}_{1}, \boldsymbol{\xi}_{2}, \ldots, \boldsymbol{\xi}_{k}\right)$, the remaining $N-k$ being anywhere is given by:

$$
\Gamma^{(k)}\left(\boldsymbol{\xi}_{1}, \boldsymbol{\xi}_{2}, \ldots, \boldsymbol{\xi}_{k}\right)=\frac{N !}{(N-k) !} \int d \boldsymbol{\tau}_{k+1} \int d \boldsymbol{\tau}_{k+2} \ldots \int d \boldsymbol{\tau}_{N} P_{N}\left(\boldsymbol{\xi}_{1}, \boldsymbol{\xi}_{2}, \ldots, \boldsymbol{\xi}_{k},\right.
$$

Particularly important are the first and second order distribution functions $\Gamma^{(1)}(\boldsymbol{\xi})$ and $\Gamma^{(2)}\left(\boldsymbol{\xi}, \boldsymbol{\xi}^{\prime}\right)$. Integration of $\Gamma^{(1)}(\boldsymbol{\xi})$ over the spin coordinate $\boldsymbol{\sigma}$ yields the electron density $\rho(\mathbf{r})$, since the spin coordinate is discrete this integration is actually the sum of two contributions $\rho_{\alpha}(\mathbf{r})$ and $\rho_{\beta}(\mathbf{r})$ which correspond to the two values $\pm \frac{1}{2}$ of $\boldsymbol{\sigma}$ :

$$
\rho(\mathbf{r})=\rho_{\alpha}(\mathbf{r})+\rho_{\beta}(\mathbf{r})
$$


The procedure described above to get the electron density and its spin components is applied to $\Gamma^{(2)}\left(\boldsymbol{\xi}, \boldsymbol{\xi}^{\prime}\right)$ in order to obtain the pair function and its four spin components:

$$
\begin{aligned}
\Pi\left(\mathbf{r}, \mathbf{r}^{\prime}\right) & =\iint \Gamma^{(2)}\left(\boldsymbol{\xi}, \boldsymbol{\xi}^{\prime}\right) d \boldsymbol{\sigma} d \boldsymbol{\sigma}^{\prime} \\
& =\Pi_{\alpha \alpha}\left(\mathbf{r}, \mathbf{r}^{\prime}\right)+\Pi_{\alpha \beta}\left(\mathbf{r}, \mathbf{r}^{\prime}\right)+\Pi_{\beta \alpha}\left(\mathbf{r}, \mathbf{r}^{\prime}\right)+\Pi_{\beta \beta}\left(\mathbf{r}, \mathbf{r}^{\prime}\right)
\end{aligned}
$$

Though the pair function appears to be the suitable quantity enabling the discussion of the pairing, it is a six-dimensional function and therefore it should be helpful to grasp its properties in a 3-dimensions mathematical object. It is convenient to define the conditional probability as

$$
\frac{\Pi_{\sigma \sigma^{\prime}}\left(\mathbf{r}, \mathbf{r}^{\prime}\right)}{\rho_{\sigma^{\prime}}\left(\mathbf{r}^{\prime}\right)}=\rho_{\sigma}(\mathbf{r})\left[1+f_{\sigma \sigma^{\prime}}\left(\mathbf{r}, \mathbf{r}^{\prime}\right)\right]
$$

where $\sigma$ and $\sigma^{\prime}$ stand for the spin labels. The function $f_{\sigma \sigma^{\prime}}\left(\mathbf{r}, \mathbf{r}^{\prime}\right)$ is the correlation factor and the product $\rho_{\sigma}(\mathbf{r}) f_{\sigma \sigma^{\prime}}\left(\mathbf{r}, \mathbf{r}^{\prime}\right)$ describes the correlation hole around the reference electron. According to the values of $\sigma$ and $\sigma^{\prime}$ there are two kinds of correlation holes: the Coulomb hole $\left(\sigma \neq \sigma^{\prime}\right)$ accounts for the Coulombic interaction whereas the antisymmetry of the wavefunction is responsible for the Fermi hole $\left(\sigma=\sigma^{\prime}\right)$.

The representation of the conditional probability, also called the LennardJones function, (Lennard-Jones, 1952; Gillespie et al., 1998) or of the Fermi hole requires to fix the position of the reference electron. The contour maps (Luken, 1984; Luken \& Culberson, 1984; Bader et al., 1996b) clearly reveal the electron pairing and yield patterns anticipated by the VSEPR model. The difficulty raised by the choice of the reference electron location led to develop different methods such as the Fermi hole mobility (Luken \& Culberson, 1982), which represents the rate of change of the shape of the Fermi hole with respect to motion of the probe electron. Another related method is the domain averaged Fermi hole developed by R. Ponec and co-workers (Ponec, 1997, 1998; Ponec \& Duben, 1999; Ponec \& Roithova, 2001; Cooper \& Ponec, 2008; Ponec et al., 2008) defined as:

$$
g_{\Omega}(\mathbf{r})=\rho(\mathbf{r}) \int_{\Omega} \rho\left(\mathbf{r}^{\prime}\right) d \mathbf{r}^{\prime}-\int_{\Omega} \Pi\left(\mathbf{r}, \mathbf{r}^{\prime}\right) d \mathbf{r}^{\prime}
$$

which corresponds to a reference electron localized in the domain $\Omega$. Strictly speaking eq. 7 describes a "domain averaged exchange-correlation hole" rather than a "domain averaged Fermi hole" since this expression involves spinless densities. 
The Electron Localization Function (ELF) was originally designed by Becke and Edgecombe to identify "localized electronic groups in atomic and molecular systems" (Becke \& Edgecombe, 1990).

$$
E L F=\eta(\mathbf{r})=\frac{1}{1+\chi(\mathbf{r})^{2}}
$$

It relies, through its kernel, $\chi(\mathbf{r})$ on the laplacian of the conditional same spin pair probability scaled by the homogeneous electron gas kinetic energy density:

in which

$$
\chi_{\sigma}(\mathbf{r})=\frac{D_{\sigma}(\mathbf{r})}{D_{\sigma}^{0}(\mathbf{r})}
$$

$$
D_{\sigma}(\mathbf{r})=t_{\sigma}(\mathbf{r})-\frac{1}{4} \frac{\left(\rho_{\sigma}(\mathbf{r})\right)^{2}}{\rho_{\sigma}(\mathbf{r})}=t_{\sigma}(\mathbf{r})-t_{\sigma}^{W}(\mathbf{r})
$$

where $\tau_{\sigma}(\mathbf{r})$ is the $\sigma$ spin contribution to the positive definite kinetic energy density. For a closed shell singlet $D_{\sigma}(\mathbf{r})$ is the difference between the total positive definite kinetic energy density $T_{s}(\mathbf{r})$ and the von Weizsäcker kinetic energy density functional $T_{v W}(\mathbf{r})$,(von Weizsäcker, 1935):

$$
D_{\sigma}(\mathbf{r})=T_{s}(\mathbf{r})-T_{v W}(\mathbf{r})
$$

whereas

$$
D_{\sigma}^{0}(\mathbf{r})=\frac{3}{5}\left(6 \pi^{2}\right)^{2 / 3} \rho_{\sigma}^{5 / 3}(\mathbf{r})
$$

is the kinetic energy density of the homogeneous electron gas. This formulation led to an interpretation of ELF in terms of the local excess kinetic energy because the Pauli repulsion enabled its calculation from Kohn-Sham orbitals. (Savin et al., 1991, 1992, 1997) Orbital-based interpretations of ELF have been proposed by Burdett (Burdett \& McCormick, 1998) and more recently by Nalewajski et al. (Nalewajski et al., 2005) who considered the non additive interorbital Fisher information. Another route pioneered by Dobson (Dobson, 1991) explicitly considers the pair functions. It has been independently developed by Kohout et al. with the Electron Localization Indicator (ELI) (Kohout et al., 2004, 2005; Wagner et al., 2007) and by one of us, (Silvi, 2003) with the spin pair composition $c_{\pi}(\mathbf{r})$ enabling to generalize ELF to correlated wave functions. (Matito et al., 2006)

From a simple statistical viewpoint, the concept of electron density localization at a given position $\mathbf{r}$ relies on the definition of a local standard deviation of the electron density. This can be achieved either by a procedure due to P. Ayers who introduced the local covariance measure (Ayers, 2005)

$$
\xi_{\sigma}^{h}(\rho ; \mathbf{r})=\rho^{\sigma} \int h^{\sigma \sigma}\left(\mathbf{r}, \mathbf{r}^{\prime}\right) d \mathbf{r}^{\prime}
$$


the evaluation of which requires a model for the correlation hole or by the finite sampling procedure described below which considers the standard deviation of the electron density integrated over a sampling volume $V(\mathbf{r})$ encompassing the reference point and containing a given quantity of matter, in other words a given charge $q$. The smaller the standard deviation is, the higher the localization is. Instead of the standard deviation, it is advantageous to use its square, the variance $\sigma^{2}$, which can be expressed as the expectation value of the variance operator (Diner \& Claverie, 1976; Silvi, 2004):

$$
\begin{aligned}
\left\langle\hat{\sigma}^{2}(\bar{N}[V(\mathbf{r})])\right\rangle & =\bar{\Pi}(V(\mathbf{r}), V(\mathbf{r}))-\bar{N}(V(\mathbf{r}))(\bar{N}(V(\mathbf{r}))-1) \\
& =\bar{\Pi}(V(\mathbf{r}), V(\mathbf{r}))-q^{2}+q
\end{aligned}
$$

in which $\bar{N}(V(\mathbf{r}))=q$ and $\bar{\Pi}(V(\mathbf{r}), V(\mathbf{r}))$ are respectively the one particle and two particle densities integrated over the sample $V(\mathbf{r})$. In the expression of the variance given above, only $\bar{\Pi}(V(\mathbf{r}), V(\mathbf{r}))$ is function of the position and therefore $-q^{2}+q$ can be regarded as a constant and deleted. The integrated pair density is the sum of an opposite spin contribution, $2 \bar{\Pi}^{\alpha \beta}(V(\mathbf{r}), V(\mathbf{r}))$ almost proportional to $q^{2}$ and of a same spin contribution $\bar{\Pi}^{\alpha \alpha}(V(\mathbf{r}), V(\mathbf{r}))+$ $\bar{\Pi}^{\beta \beta}(V(\mathbf{r})$. The expectation value of the variance of the integrated opposite spin pair density,

$$
\begin{aligned}
\left\langle\hat{\sigma}^{2}\left(\bar{\Pi}^{\alpha \beta}(V(\mathbf{r}), V(\mathbf{r}))\right)\right\rangle= & \bar{\Pi}^{\alpha \alpha}(V(\mathbf{r}), V(\mathbf{r})) \bar{\Pi}^{\beta \beta}(V(\mathbf{r}), V(\mathbf{r})) \\
& +\bar{N}^{\alpha}(V(\mathbf{r})) \bar{\Pi}^{\beta \beta}(V(\mathbf{r}), V(\mathbf{r})) \\
& +\bar{N}^{\beta}(V(\mathbf{r})) \bar{\Pi}^{\alpha \alpha}(V(\mathbf{r}), V(\mathbf{r}))+\bar{N}^{\alpha}(V(\mathbf{r})) \bar{N}^{\beta}(V(\mathbf{r})) \\
& -\left(\bar{\Pi}^{\alpha \beta}(V(\mathbf{r}))\right)^{2}
\end{aligned}
$$

also depends upon the integrated same spin pair densities. The integrated same spin pair density has numerically been shown proportional to a function of the reference point position, say $c_{\pi}(\mathbf{r})$, times $q^{5 / 3}$. In the limit $q=0$, the ratio

$$
\frac{\bar{\Pi}(V(\mathbf{r}), V(\mathbf{r}))}{q^{5 / 3}}
$$

tends to the spin pair composition, $c_{\pi}(\mathbf{r})$, a local function independent from the size of the sample (Silvi, 2003). The ability of this function to localize "electronic groups" can be illustrated by a very simple example in which two $\alpha$ and two $\beta$ spin electrons are confined in a box of volume $\Omega$ as represented in figure 1.

〈 figure 1 near here 〉 
For the sake of simplicity we assume the electron density probability to be uniform, i. e. $\rho(\mathbf{r})=4 / \Omega$ without spin polarization $\left(\rho^{\alpha}(\mathbf{r})=\rho^{\beta}(\mathbf{r})=2 / \Omega\right.$, such as the opposite spin pair functions, $\Pi^{\alpha \beta}\left(\mathbf{r}_{1}, \mathbf{r}_{2}\right)=\Pi^{\beta \alpha}\left(\mathbf{r}_{1}, \mathbf{r}_{2}\right)=4 / \Omega^{2}$ are constant. This model enables to consider two localization cases. On the one hand, the opposite spin pairs are delocalized over the box and the same spin pair functions are constant: $\Pi^{\alpha \alpha}\left(\mathbf{r}_{1}, \mathbf{r}_{2}\right)=\Pi^{\beta \beta}\left(\mathbf{r}_{1}, \mathbf{r}_{2}\right)=2 / \Omega^{2}$ and therefore $c_{\pi}(\mathbf{r})$ is also constant. On the other hand, each opposite spin pair occupies one half of the box such as:

$$
\Pi^{\alpha \alpha}\left(\mathbf{r}_{1}, \mathbf{r}_{2}\right)=\Pi^{\beta \beta}\left(\mathbf{r}_{1}, \mathbf{r}_{2}\right)= \begin{cases}0 & \mathbf{r}_{1}, \mathbf{r}_{2} \in \text { same half box } \\ 4 / \Omega^{2} & \mathbf{r}_{1}, \mathbf{r}_{2} \in \text { different half boxes }\end{cases}
$$

It follows that

$$
c_{\pi}(\mathbf{r}) \begin{cases}=0 & \mathbf{r} \notin \text { the boundary } \\ \propto 4 / \Omega^{2} & \mathbf{r} \in \text { the boundary }\end{cases}
$$

which enables to locate the boundary between the two opposite spin pair regions. For Hartree-Fock wavefunction, it can be easily demonstrated (Silvi, 2003) that:

$$
c_{\pi}(\mathbf{r}) \approx \chi_{\sigma}(\mathbf{r})
$$

The ELF itself is further obtained through the transformation of $\chi_{\sigma}(\mathbf{r})$ into a lorentzian function

$$
\eta(\mathbf{r})=\frac{1}{1+\chi_{\sigma}^{2}(\mathbf{r})}
$$

so as it tends to 1 in those regions where the localization is high and to small values at the boundaries between such regions.

There exist other localization functions based on other criteria such as the "localized orbital locator" (LOL) (Schmider \& Becke, 2000) which relies of the positive definite kinetic energy density and the "electron pair localization function" (EPLF) (Scemama et al., 2004) which considers the averaged distance between a reference electron and the closest spin-like or spin unlike electron of the system.It is worth noting that several proposals have been made in order to evaluate $E L F$ from experimental densities (Tsirelson \& Stash, 2002; Jayatilaka \& Grimwood, 2004).

\subsection{Revisiting some chemical concepts}

The purpose is not to justify or invalidate the Lewis's and VSEPR models but rather to establish correspondences between the concepts they assume and quantum mechanics. 


\subsubsection{Spatial arrangement of valence electrons}

The spatial arrangement of electrons and electron pairs is a key concept of the two models since it enables to distinguish bonding from non bonding pairs. As electron are not at fixed positions, electron positions are not helpful. However, the distribution function $\Gamma^{(N)}\left(\boldsymbol{\xi}_{1}, \boldsymbol{\xi}_{2}, \ldots, \boldsymbol{\xi}_{N}\right)$ (eq. 2) describes the probability of finding the systems at the configuration given by the list of the arguments. Therefore, an equivalence can made between the $\Gamma^{(N)}$ maxima electron positions and the arrangement of the $N$ electrons in the models. This can be graphically represented by plotting $N$ points at the values of the arguments of $\Gamma^{(N)}$ at a maximum, the spin being indicated by the color of the point. The $N / 2$ opposite spin pairs are further selected on a distance criterion. It has been initially proposed to consider the electron coordinates of the absolute maximum of $\Gamma^{(N)}$ (Artmann, 1946; Howard K. Zimmerman \& Rysselberghe, 1949) but distribution functions may have either several maxima close in magnitude if the point group of the geometry of the nuclei is finite or continua of maxima otherwise. Moreover, equivalent maxima are generated by spin inversion. The most probable valence electron arrangements in the water molecule has been recently investigated (Scemama et al., 2007) for both Hartree-Fock and correlated (VQMC) wave functions. The single determinant wave function yields a tetrahedral arrangement of opposite spin electron pairs (figure 2(a)). It corresponds to the expectation made by Lewis in order to explain the tetrahedral carbon and the formation of triple bonds and also to the VSEPR $\mathrm{AX}_{2} \mathrm{E}_{2}$ type. The account for Coulomb correlation separates the two electrons of each pair and gives rise, among others, to the configurations of figure 2(b) and (c). Configuration (d) recovers both Lewis's cubic model and Linnett double quartet. It is worth noting that Lewis anticipated the multiplicity of spatial configurations with the concept of tautomerism (Lewis, 1916):

In such cases we have the phenomenon of tautomerism, where two or more forms of the molecule pass readily into one another and exist together in a condition of mobile equilibrium. ... In the simplest case where we deal with a single tautomeric change we speak of the two tautomers and sometimes write definite formulae to express the two. But we must not assume that all of the molecules of the substance possess either one structure or the other, but rather that these forms represent the two limiting types, and that the individual molecules range all the way from one limit to the other.

〈 figure 2 near here 〉 
The spatial organization of the couples of opposite spin electron positions which maximizes $\Gamma^{(N)}$ enables to identify which pairs belong to the valence shells of two atoms and which others to the valence shell of just one atom and gives sense to the concepts of bonding and non-bonding pairs in agreement with Lewis's definition of the bond (Lewis, 1966):

Two electrons thus coupled together, when lying between two atomic centers, and held jointly in the shells of two atoms, I have considered to be the chemical bond.

\subsubsection{Electron pair domains}

Instead of considering the maxima of $\Gamma^{(N)}$, it should interesting consider the spatial extension of opposite spin electron pairs and therefore to investigate the regions in which the probability of finding them are large. A first kind of technique enabling a quantitative study, the loge theory (Daudel, 1953; Daudel et al., 1954, 1955), has been developed for this purpose in the fifties by $\mathrm{R}$. Daudel and co-workers. The loge theory divides the space in $p$ connected non overlapping volumes, $V_{n}$, within which one has to evaluate the probability $P_{n}$ of finding $n$ and only $n$ electrons of given spins. The difficulty of finding the best decomposition has limited applications of the loge theory to very small systems. In the seventies, the introduction of concepts from Shannon's information theory (Shannon \& Weaver, 1949) brought some noticeable improvements (Aslangul, 1971; Aslangul et al., 1972, 1974). The performances of the computers of the seventies forbid the applications of this method to chemically interesting molecular systems.

Recently, the evaluation of $P_{n}$ has been revisited by Cancès et al (Cancès et al., 2004) who derived a series of efficient recurrence formulas in the case of a single determinant representation of the wave functions. An algorithm optimizing the shape of the maximum probability domains (MPDs), $\Omega_{n}$, has been designed accordingly and applied to linear molecules (Gallegos et al., 2005) and other simple molecules (Scemama et al., 2007). This approach which applies to any multiplet in any spin configuration and therefore is not limited to the determination of opposite spin pair MPDs. For example, it had been recently used to characterize ions in rock-salt structures (Causà \& Savin, 2011). For a given value of $n<N$ there are several solutions. In the case of closed shell $N$-electron systems $N / 2$ opposite spin pair MPDs are expected which correspond to the core, valence bonding and valence non bonding pairs. It often happens that more MPDs can be determined. This is the case of the $\mathrm{FHF}^{-}$complex where two symmetry related overlapping domains containing the proton correspond to the two $\mathrm{F}-\mathrm{H}$ bonds. In this 
particular case, the overlap of the domain is interpreted as a manifestation of the resonances between the $\left[\mathrm{F}-\mathrm{H}+\mathrm{F}^{-}\right]$and $\left[\mathrm{F}^{-}+\mathrm{HF}\right]$ structures.

The single electron densities (SEDs) of Lüchow and Petz (Lüchow \& Petz, 2011) provide a partition of the total density in terms of single electron contributions containing the many-body information from the wave function. The method is technically based on an assignment of the electrons which corresponds to a selection by a distance criterion of the permutations which leaves constant the number of electrons assigned to core, bonds, lone pairs, etc.

A partition of the space in adjacent non overlapping regions can be achieved by applying the dynamical system theory (Abraham \& Marsden, 1994) to the ELF gradient field. (Silvi \& Savin, 1994; Häussermann et al., 1994a) This yields basins of attractors which can be thought as corresponding to atomic cores, bonds, and lone pairs and therefore recovering the Lewis picture of bonding and the electronic domains of the VSEPR approach. In a limit model built with perfectly localized orbitals, the ELF basins and MPDs are identical (Savin, 2005). However, in the cases where the MPD approach yields overlapping domains the ELF basins provide an averaged picture which resemble the Ingold's mesomeric state (Ingold, 1934). Integration of the one electron density over an ELF basin yields the basin population which often noticeably deviates from 2, the population of an electron pair MPD. The core basins surround nuclei with atomic number $\mathrm{Z}>2$ and are labeled $\mathrm{C}(\mathrm{A})$ where $\mathrm{A}$ is the atomic symbol of the element. The union of the valence basins encompassing a given core $\mathrm{C}(\mathrm{A})$ constitutes the valence shell of atom $\mathrm{A}$. A valence basin may be shared by several valence shells, this is a generalization of Lewis's fourth postulate "Two atomic shells are mutually interpenetrable" (Lewis, 1916). The valence basins are characterized by the number of atomic valence shells to which they participate, or in other words by the number of core basins with which they share a boundary. This number is called the synaptic order. Thus, there are monosynaptic, disynaptic, trisynaptic basins, and so on. Monosynaptic basins, labeled V(A), correspond to the lone pairs of the Lewis model and polysynaptic basins, $\mathrm{V}(\mathrm{A}, \mathrm{B}, \mathrm{C}, \ldots)$, to the shared pairs of the Lewis model. In particular, disynaptic basins correspond to two-centre bonds and trisynaptic basins to three-centre bonds, and so on (Silvi, 2002). In the example of the furan molecule displayed figure 3 the oxygen valence shell delineated by a red dotted line results of the union of the two $\mathrm{V}(\mathrm{C}, \mathrm{O})$ basins corresponding to the $\mathrm{C}-\mathrm{O}$ bonds and of the $\mathrm{V}(\mathrm{O})$ of the oxygen lone pair. In a carbon valence shell there are two $\mathrm{V}(\mathrm{C}, \mathrm{C})$ and one $\mathrm{V}(\mathrm{C}, \mathrm{H})$, this latter constituting the hydrogen valence shell. Three examples of multi-centre bonds are given in figure 4. The ELF picture of diborane recovers the protonated double bond picture of Pitzer (Pitzer, 1946) in which 
the two boron atoms are linked by two trisynaptic basins embedding a proton, in $\mathrm{C}_{2} \mathrm{H}_{4}\left(\mathrm{AlCH}_{3}\right)_{2}$ the two $\mathrm{V}(\mathrm{C}, \mathrm{Al}, \mathrm{C})$ basins account for the addition of the $\mathrm{AlCH}_{3}$ on the $\mathrm{C}_{2} \mathrm{H}_{4}$ molecule given for comparison. Finally, in the lithium crystal the ELF valence basin occupy the octahedral interstitial site.

\subsubsection{ELF basins and VSEPR domain.}

The topology of the laplacian of the charge density has been invoked as a physical basis of the VSEPR model (Bader et al., 1988). Qualitatively, the valence shell charge concentrations (VSCCs) of the central atom correspond to the electronic domains of the model (Gillespie, 1991; Gillespie \& Robinson, 1996) and they have also been used to explain the geometries of non-VSEPR molecules (Gillespie et al., 1996). From a quantitative point of view, Malcolm and Popelier attempted to justify the assumptions on the domain sizes considering the full topology of the laplacian of the charge density (Malcolm \& Popelier, 2003). They conclude that non bonding domains are larger than bonding domains of the same valence shell and that multiple bond domains are larger than single bond ones, but the full topology of the laplacian fails to account for the the electronegativity effects.

Although the ELF basins do not exactly fulfill the requirements of the VSEPR electronic domain definition, Gillespie and Robinson wrote (Gillespie \& Robinson, 2007):

These basins correspond to the qualitative electron pair domains of the VSEPR model and have the same geometry as the VSEPR domains.

The VSEPR model relies on the interaction between the electronic domains around a given atomic center which is ruled by either electrostatic forces in the earliest version and on the relative size of the domain in the last version. The electrostatic repulsion between ELF valence basins, $\Omega$ and $\Omega^{\prime}$ has been investigated by Martín Pendás et al (Martín Pendás et al., 2008) who considered the integral

$$
V_{e e}^{\Omega, \Omega^{\prime}}=\int_{\Omega} d \mathbf{r}_{1} \int_{\Omega^{\prime}} \frac{\pi\left(\mathbf{r}_{1}, \mathbf{r}_{2}\right)}{\mid \mathbf{r}_{2}-\mathbf{r}_{1}} d \mathbf{r}_{2}
$$

They found a very fair agreement with the VSEPR assumptions: monosynaptic basins (lone pairs) are more repulsive than disynaptic ones, multiple bonds are more repulsive than single bonds, the repulsion decreases when the electronegativity of the substituent implied in the disynaptic basin increases. A thorough analysis of the ELF basin volumes has been carried out on a 
sample of about 150 molecules (Silvi \& Gillespie, 2007). Since valence basins may in principle extend to infinity the molecular space has been limited by the density isosurface $\rho(\mathbf{r})=10^{-4}$ which ensures less than $0.2 e$ are not considered in each molecule. The volumes of the $\mathrm{V}(\mathrm{X}), \mathrm{V}(\mathrm{X}, \mathrm{H})$ and $\mathrm{V}(\mathrm{X}, \mathrm{X})$ basins are nicely anti correlated with the electronegativity $\chi(\mathrm{X})$ of the $\mathrm{X}$ atom, they decrease as $\chi(\mathrm{X})$ increases and are moreover independent of the period of the element. Around the $\mathrm{X}$ centre the $\mathrm{V}(\mathrm{A}, \mathrm{X})$ basins are always smaller than the $\mathrm{V}(\mathrm{X})$ ones whereas the $\mathrm{V}(\mathrm{X}, \mathrm{H})$ are smaller for $\mathrm{X}$ belonging to the third and fourth periods and almost equal for the second period elements. The case of the hydrogen ligand is however particular because the proton is embedded in the basin which is not the case of the nucleus and core basin of other ligands. For elements of the same group and a given ligand the volume of the $\mathrm{V}(\mathrm{A}, \mathrm{X})$ basin increases with the period (and in some extent with the decrease of the electronegativity of the central atom), for example the $\mathrm{V}(\mathrm{Si}, \mathrm{F})$ basin volume is twice that of $\mathrm{V}(\mathrm{C}, \mathrm{F})$. Finally, the multiple bonds yield basin larger than single bonds mostly for geometrical reason: in the case of a $\mathrm{A}=\mathrm{B}$ double bond the basins are located on both sides of the plane containing the ligands of $\mathrm{A}$ and $\mathrm{B}$. Therefore the repulsion from the ligands is weaker than for a single A-B bond, for example the volume of each $\mathrm{V}(\mathrm{C}, \mathrm{O})$ basin of formaldehyde is calculated to be ten times larger than that of methanol.

The analysis of the core basin volumes and of the shapes of the outermost core shells shows that these properties cannot be always neglected in bonding models which provides indications for further improvements of such models.

\subsubsection{Bonding classification of chemical interactions}

In the description provided by ELF, an atom $\mathrm{X}$ in a molecule is composed of its nucleus and of the electron density of its core and valence basins which form its valence shell. As already mentioned a valence basin may belong to the valence of different atoms and therefore two atoms bonded by a disynaptic basin do overlap. This description is consistent with the Lewis's atom and differs from the QTAIM atoms which are non overlapping bodies. In the QTAIM framework the interactions have been initially divided in "shared electron " and "closed shell (or unshared electron)" interaction classes according to the sign of the laplacian of the electron density at the bond critical point (Bader \& Essén, 1984; Bader, 1990). Other indicators such as the energy density at the BCP (Cremer \& Kraka, 1984, 1983; Kraka \& Cremer, 1992) and the delocalization indexes (Fradera et al., 1998) have been further introduced in order to refine the classification of interactions and to approach the current chemical terminology (Bianchi et al., 2000; Macchi et al., 1998; 
Mori-Sánchez et al., 2002).

The dichotomous classification into "shared electron" and "unshared electron" interaction classes naturally emerges from the organisation of the ELF basins. The "shared electron" interaction implies the presence of a disynaptic or polysynaptic basin and gathers the covalent, dative and metallic types of bond which can be further discriminated on the basis of other criteria such as the dissociation products or the flatness of the function at it valence maxima. The "unshared electron" class consists on the one hand of interactions governed by electrostatic or dispersion forces (ionic bonding, Hydrogen bonding, van der Waals complexes) and on the other hand of interactions in which electron delocalization plays a dominant role (two-center three-electron bonding, charge-shift bonding). The calculation of the basin populations and basin electrostatic moments (Pilme \& Piquemal, 2008) sheds light on the electrostatic aspects of the bonding whereas the basin population variances and covariances (Savin et al., 1996; Silvi, 2004) provide a measure of the delocalization. Examples of application to metallic bond (Silvi \& Gatti, 2000), two-center three-electron bonding (Fourré \& Silvi, 2007) and charge-shift bonding (Shaik et al., 2005) can be found in the literature.

\section{Conclusions}

The statistical approaches provide, at least formally, mathematical bridges between quantum mechanics and chemistry which enable to critically think about the content and the definition of many chemical concepts. The improvement of these latter can be achieved in order to remove any assumption in contradiction with the laws of quantum mechanics and take into account important features which had been nelected. The substitution of a classical statement by its statistical formulation is often sufficient to make it consistent. The chemical objects used in the bonding models (electron pairs, electronic domains, valence shells) are not physical observables but correspondences can be established with objects defined in the statistical frameworks (loges, MPDs, basins). These approaches are on the way to solve the historical problems of communication between chemical phenomenological systems and quantum mechanics.

Chemistry and physics belong to the same universe but often use their proper objects and their proper laws because they have to explain different phenomena. The laws of chemistry account for the complexity and the diversity of the matter in a rather qualitative fashion which embodies the physical laws. In fact, there is not a unique level of understanding and nobody is obliged to strictly follow the unification account. Although quantum 
electrodynamics is the physical theory which treats the interaction of light with matter it is of little help to explain how works a telescope for which classical geometric optics provides a satisfactory answer. In the same way, the explanations of chemical phenomena based on chemical concepts are indisputably useful since they grasp the salient feature. As an example, we can mention a paper of C. Gourlaouen and O. Parisel (Gourlaouen \& Parisel, 2007) in which the authors addressed the electronic origin of lead toxicity. In brief, the calmodulin protein forms complexes with $\mathrm{Ca}^{++}$which are involved in important biological processes such as mitosis neurotransmission, and regulation of the calcium pump. In these complexes the calcium dication is heptacoordinated. Substitution of $\mathrm{Ca}^{++}$by $\mathrm{Pb}^{++}$induces strong spatial distorsions which modify the properties of the complex. The striking chemical difference in the ELF pictures of the $\mathrm{Ca}^{++}$and $\mathrm{Pb}^{++}$bioinspired model complexes is the presence of a lone pair basin on the lead centre which then provides a VSEPR type explanation of the distorsions of the $\mathrm{Pb}^{++}$complex with respect to the $\mathrm{Ca}^{++}$one. 


\section{References}

Abegg, A. (1904). Die valenz und das periodische system. versuch einer theorie der molekularverbindungen. Z. anorg. Chem., 39, 330-380.

Abraham, R. H. \& Marsden, J. E. (1994). Foundations of Mechanics. Redwood City, CA: Addison Wesley.

Alvarez, S., Hoffmann, R., \& Mealli, C. (2009). A bonding quandary-or-a demonstration of the fact that scientists are not born with logic. Chem. Eur. J., 15(34), 8358-8373.

Artmann, K. (1946). Zur quantentheorie der gewinkelten valenz, i. mitteilung: Eigenfunktion und valenzbetätigung des zentralatoms. Z. Naturf., 1, 426-432.

Aslangul, C. (1971). Introduction of information theory in study of electron localizability in atoms and molecules. Compt. Rend. Acad. Sci. Ser. B, 272(1), 1.

Aslangul, C., Constanciel, R., Daudel, R., Esnault, L., \& Ludeña, E. V. (1974). The loge theory as a starting point for variational calculations. i. general formalism. Int. J. Quant. Chem., 8, 499-522.

Aslangul, C., Constanciel, R., Daudel, R., \& Kottis, P. (1972). Aspects of the localizability of electrons and molecules: Loge theory and related methods. In P.-O. Löwdin (Ed.), Advances in Quantum Chemistry, volume 6 (pp. 93-141). New York: Academic Press.

Ayers, P. W. (2005). Electron localization functions and local measures of the covariance. J. Chem. Sci., 117, 441-454.

Bader, R. F. W. (1964). Binding regions in polyatomic molecules and electron density distributions. J. Am. Chem. Soc., 86, 5070-5075.

Bader, R. F. W. (1975). Molecular fragments or chemical bonds? Acc. Chem. Res., 8, 34-40.

Bader, R. F. W. (1985). Atoms in molecules. Acc. Chem. Res., 18, 9-15.

Bader, R. F. W. (1990). Atoms in Molecules: A Quantum Theory. Oxford: Oxford Univ. Press.

Bader, R. F. W. (1991). A quantum theory of molecular structure and its applications. Chem. Rev., 91(5), 893-928. 
Bader, R. F. W. (2005). The quantum mechanical basis of conceptual chemistry. Monatshefte für Chemie, 136, 819-854.

Bader, R. F. W. (2007). Everyman's derivation of the theory of atoms in molecules. J. Phys. Chem. A, 111, 7966-7972.

Bader, R. F. W. (2011). On the non-existence of parallel universes in chemistry. Found. Chem., 13, 11-37.

Bader, R. F. W., Beddall, P. M., \& Cade, P. E. (1971). Partitioning and characterization of molecular charge distributions. J. Am. Chem. Soc., 93, 3095-3107.

Bader, R. F. W. \& Essén, H. (1984). The characterization of atomic interactions. J. Chem. Phys., 80, 1943-1960.

Bader, R. F. W., Gillespie, R. J., \& MacDougall, P. J. (1988). A physical basis for the vsepr model of molecular geometry. J. Am. Chem. Soc., 110, $7329-7336$.

Bader, R. F. W., Henneker, W. H., \& Cade, P. E. (1966). Molecular charge distributions and chemical binding. J. Chem. Phys., 46, 3341-3363.

Bader, R. F. W., Johnson, S., Tang, T.-H., \& Popelier, P. L. A. (1996a). The electron pair. J. Phys. Chem., 100, 15398-15415.

Bader, R. F. W. \& Matta, C. F. (2012). Atoms in molecules as nonoverlapping, bounded, space-filling open quantum systems. Found. Chem., (pp. in press).

Bader, R. F. W. \& Nguyen-Dang, T. T. (1981). Quantum theory of atoms in molecules -dalton revisited. In Advances in Quantum Chemistry, volume 14 (pp. 63-124). New York: Academic Press.

Bader, R. F. W., Nguyen-Dang, T. T., \& Tal, Y. (1979). Quantum topology of molecular charge distributions. ii. molecular structure and its change. J. Chem. Phys., 70, 4316-4329.

Bader, R. F. W., Streitwieser, A., Neuhaus, A., Laidig, K. E., \& Speers, P. (1996b). Electron delocalization and the fermi hole. J. Am. Chem. Soc., 118, 4959-4965.

Becke, A. D. \& Edgecombe, K. E. (1990). A simple mesure of electron localization in atomic and molecular systems. J. Chem. Phys., 92, 53975403. 
Bianchi, R., Gervasio, G., \& Marabello, D. (2000). Experimental electron density analysis of $\mathrm{mn}_{2}(\mathrm{co})_{10}$ : Metal-metal and metal-ligand bond characterization. Inorg. Chem., 39, 2360-2366.

Burdett, J. K. \& McCormick, T. A. (1998). Electron localization in molecules and solids: The meaning of elf. J. Phys. Chem. A, 102, 6366-6372.

Burrau, Øjvind. (1927). Berechnung des energiewertes des wasserstoffmolekel- ions $\left(\mathrm{h}_{2}^{+}\right)$im normalzustand. Naturwissenschaften, 15 , $16-17$.

Cancès, E., Keriven, R., Lodier, F., \& Savin, A. (2004). How electrons guard the space: shape optimization with probability distribution criteria. Theor. Chem. Acc., 111, 373-380.

Causà, M. \& Savin, A. (2011). Maximum probability domains in crystals: The rock-salt structure. J. Phys. Chem. A, 115(45), 13139-13148.

Condon, E. U. (1927). Wave mechanics and the normal state of the hydrogen molecule. Proc. Nat. Acad. Sci., 13, 466-470.

Cooper, D. L. \& Ponec, R. (2008). A one-electron approximation to domainaveraged fermi hole analysis. Phys. Chem. Chem.Phys., 10, 1319-1329.

Coulson, C. A. (1952). Valence. Oxford: Clarendon.

Cremer, D. \& Kraka, E. (1983). A description of the chemical bond in terms of local properties of the electron density and energy. Croat. Chem. Acta, $57,1259-1281$.

Cremer, D. \& Kraka, E. (1984). Chemical bonds without bonding electron density - does the difference electron-density analysis suffice for a description of the chemical bond? Angew. Chem. Int. Ed. Engl., 23, 627-628.

Dalton, J. (1808). New System of Chemical Philosophy. London: R. Bickerstaff.

Daudel, R. (1953). Sur la localisabilité des corpuscules dans les noyaux et les cortèges électroniques des atomes et des molécules. Compt. Rend. Acad. Sci., 237(12), 601-603.

Daudel, R., Brion, H., \& Odiot, S. (1955). Localizability of electrons in atoms and molecules - application to the study of the notion of shell and of the nature of chemical bonds. J. Chem. Phys., 23(11), 2080-2083. 
Daudel, R., Odiot, S., \& Brion, H. (1954). Théorie de la localisabilité des corpuscules .1. la notion de loge et la signification géometrique de la notion de couche dans le cortège électronique des atomes. J. Chim. Phys., 51(2), $74-77$.

De Proft, F. \& Geerlings, P. (2001). Conceptual and computational dft in the study of aromaticity. Chem. Rev., 101, 1451-1464.

Del Re, G. (2003). Reaction mechanisms and chemical explanation. Annals of the New York Academy of Sciences, 988(1), 133-140.

Diner, S. \& Claverie, P. (1976). Statistical and stochastic aspects of the delocalization problem in quantum mechanics. In O. Chalvet, R. Daudel, S. Diner, \& J. P. Malrieu (Eds.), Localization and Delocalization in Quantum Chemistry, volume II (pp. 395-448). Dordrecht: Reidel.

Dirac, P. A. M. (1929). Quantum mechanics of many-electron systems. Proc. Roy. Soc. A, 123, 714-733.

Dobson, J. F. (1991). Interpretation of the fermi hole curvature. J. Chem. Phys., 94, 4328-4333.

Fourré, I. \& Silvi, B. (2007). What can we learn from two-center threeelectron bonding with the topological analysis of elf? Heteroatom Chemistry, 18, 135-160.

Fradera, X., Austen, M. A., \& Bader, R. F. W. (1998). The lewis model and beyond. J. Phys. Chem. A, 103, 304-314.

Francisco, E., Pendás, A. M., \& Blanco, M. A. (2007). Electron number probability distributions for correlated wave functions. J. Chem. Phys., 126(9), 094102.

Friedman, M. (1974). Explanation and scientific understanding. Journal of Philosophy, 71, 5-19.

Gallegos, A., Carbo-Dorca, R., Lodier, F., Cancès, E., \& Savin, A. (2005). Maximal probability domains in linear molecules. J. Comput. Chem., 26, 455-460.

Geerlings, P., De Proft, F., \& Langenaeker, W. (2003). Conceptual density functional theory. Chem. Rev., 103, 1793-1873.

Gillespie, R. J. (1972). Molecular Geometry. London: Van Nostrand Reinhold. 
Gillespie, R. J. (1991). The vsepr model revisited. Chem. Soc. Rev., 21, 59-69.

Gillespie, R. J. (2000). Improving our understanding of molecular geometry and the vsepr model through the ligand close-packing model and the analysis of electron density distributions. Coord. Chem. Chem. Rev., 197, $51-69$.

Gillespie, R. J., Bayles, D., Platts, J., Heard, G. L., \& Bader, R. F. W. (1998). The lennard-jones function: A quantitative description of the spatial correlation of electrons as determined by the exclusion principle. $J$. Phys. Chem. A, 102, 3407-3414.

Gillespie, R. J., Bytheway, I., Tang, T.-H., \& Bader, R. F. W. (1996). Geometry of the fluorides, oxofluorides, hydrides, and methanides of vanadium(v), chromium(vi), and molybdenum(vi): Understanding the geometry of nonvsepr molecules in terms of core distortion. Inorg. Chem., 35, 3954-3963.

Gillespie, R. J. \& Nyholm, R. S. (1957). Inorganic stereochemistry. Quart. Rev. Chem. Soc., 11, 339-380.

Gillespie, R. J. \& Popelier, P. L. A. (2001). Chemical Bonding and Molecular Geometry. Oxford: Oxford University Press.

Gillespie, R. J. \& Robinson, E. A. (1996). Electron domains and the vsepr model of molecular geometry. Angew. Chem. Int. Ed. Engl., 35, 495-514.

Gillespie, R. J. \& Robinson, E. A. (2007). Models of molecular geometry. J. Comput. Chem., 28, 87-97.

Gourlaouen, C. \& Parisel, O. (2007). Is an electronic shield at the molecular origin of saturnism? a computational modelling experiment. Angew. Chem., 119, 559-562.

Häussermann, U., Wengert, S., \& Nesper, R. (1994a). Localization of electrons in intermetallic phases containing aluminium. Angew. Chem. Int. Ed. Engl., 33, 2069-2072.

Häussermann, U., Wengert, S., \& Nesper, R. (1994b). Unequivocal partitioning of crystal structures. exemplified by intermetallic phases containing aluminium. Angew. Chem. Int. Ed. Engl., 33, 2073-2076.

Heelan, P. A. (2003). Paradoxes of measurement. Annals of the New York Academy of Sciences, 988(1), 114-127. 
Heitler, W. \& London, F. (1927). Wechselwirkung neutraler atome und homoöpolare bindung nach quantenmechanik. Z. Physik, 44, 455-472.

Hempel, C. G. \& Oppenheim, P. (1948). Studies in the logic of explanation. Philosophy of Science, 15, 135-175.

Hoffmann, R., Shaik, S., \& Hiberty, P. C. (2003). A conversation on vb vs mo theory: A never-ending rivalry? Acc. Chem. Res., 36, 750-756.

Howard K. Zimmerman, J. \& Rysselberghe, P. V. (1949). Directed valence as a property of determinant wave functions. The Journal of Chemical Physics, 17(7), 598-602.

Huggins, M. L. (1922). The structure of benzene. Science, 55, 679-680.

Hund, F. (1926). Zur deutung einiger erscheinungen in den molekelspektren. Z. Physik., 36, 657-674.

Hund, F. (1928). Zur deutung der molekelspektren. iv. Z. Physik., 51, 759795.

Hund, F. (1932). Zur frage der chemischen bindung. Z. Physik., 73, 1-30.

Ingold, C. K. (1922). The structure of the benzene nucleus, part i: Intranuclear tautomerism. J. Chem. Soc., 121, 1133-1143.

Ingold, C. K. (1933). Significance of tautomerism and of the reactions of aromatic compounds in the electronic theory of organic reactions. J. Chem. Soc., 143, 1120-1127.

Ingold, C. K. (1934). Mesomerism and tautomerism. Nature, 133, 946-947.

Jayatilaka, D. \& Grimwood, D. (2004). Electron localization functions obtained from x-ray constrained hartree-fock wavefunctions for molecular crystals of ammonia, urea and alloxan. Acta Cryst. A, 60, 111-119.

Kitcher, P. (1981). Explanatory unification. Philosophy of Science, 48, 507531.

Kohout, M., Pernal, K., Wagner, F. R., \& Grin, Y. (2004). Electron localizability indicator for correlared wavefunctions. i. parallel spin pairs. Theor. Chem. Acc., 112, 453-459.

Kohout, M., Pernal, K., Wagner, F. R., \& Grin, Y. (2005). Electron localizability indicator for correlared wavefunctions. i. antiparallel spin pairs. Theor. Chem. Acc., 113, 287-293. 
Kraka, E. \& Cremer, D. (1992). Description of chemical reactions in terms of the properties of the electron density. J. Mol. Struct. (Theochem), 255, 189-206.

Laming, R. (1845). Observation on a paper by prof. faraday concerning electric conduction and the nature of matter. Phil. Mag., 27, 420-423.

Lennard-Jones, J. E. (1929). The electronic structure of some diatomic molecules. Trans. Faraday Soc., 25, 668-686.

Lennard-Jones, J. E. (1952). The spatial correlation of electrons in molecules. J. Chem. Phys., 20, 1024-1029.

Lewis, G. N. (1916). The atom and the molecule. J. Am. Chem. Soc., 38, $762-786$.

Lewis, G. N. (1966). Valence and the Structure of Atoms and Molecules. New York: Dover.

Linnett, J. W. (1961). A modification of the lewis-langmuir octet rule. J. Am. Chem. Soc., 83, 2643-2653.

Linnett, J. W. (1964). The Electronic Structure of Molecules. A new approach. London: Methuen.

Lopes, Jr., O. M., Braida, B., Causa, M., \& Savin, A. (2012). Understanding Maximum Probability Domains with Simple Models. In Hoggan, PEE and Brandas, EJJ and Maruani, J and Piecuch, P and DelgadoBarrio, G (Ed.), Advances in the theory of quantum systems in chemistry and physics, volume 22 of Progress in Theoretical Chemistry and Physics (pp. 173-184). PO BOX 17, 3300 AA DORDRECHT, NETHERLANDS: Trinity Coll; Q-Chem; RSC SPRINGER. 15th International Workshop on Quantum Systems in Chemistry and Physics (QSCP), Magdalene Coll, Cambridge, ENGLAND, AUG 31-SEP 05, 2010.

Lüchow, A. \& Petz, R. (2011). Single electron densities: A new tool to analyze molecular wavefunctions. J. Comput. Chem., 32, 2619-2626.

Luken, W. L. (1984). Properties of the fermi hole in molecules. Croat. Chem. Acta, 57, 1283-1294.

Luken, W. L. \& Culberson, J. C. (1982). Mobility of the fermi hole in a single-determinant wavefunction. Int. J. Quant. Chem., 22, 265-276. 
Luken, W. L. \& Culberson, J. C. (1984). Localized orbitals based on the fermi hole. Theor. Chim. Acta (Berlin), 66, 279-293.

Macchi, P., Proserpio, D. M., \& Sironi, A. (1998). Experimental electron density in a transition metal dimer: Metal-metal and metal-ligand bonds. J. Am. Chem. Soc., 120, 13429-13435.

Malcolm, N. O. J. \& Popelier, P. L. A. (2003). The full topology of the laplacian of the electron density: scrutinising a physical basis for the vsepr model. Faraday Discuss., 124, 353-363.

Martín Pendás, A., Francisco, E., \& Blanco, M. A. (2007). Pauling resonant structures in real space through electron number probability distributions. J. Phys. Chem. A, 111(6), 1084-1090.

Martín Pendás, A., Francisco, E., \& Blanco, M. (2008). Electron-electron interactions between elf basins. Chem. Phys. Lett., 454, 396-403.

Martin Pendas, A., Francisco, E., \& Blanco, M. A. (2007). An electron number distribution view of chemical bonds in real space. Phys. Chem. Chem.Phys., 9, 1087-1092.

Martín Pendás, A., Francisco, E., \& Blanco, M. A. (2007). Spin resolved electron number distribution functions: How spins couple in real space. $J$. Chem. Phys., 127, 144103.

Matito, E., Silvi, B., Duran, M., \& Solà, M. (2006). Electron localization function at the correlated level. J. Chem. Phys., 125, 024301.

McNaught, A. D. \& Wilkinson, A. (1997). Compendium of Chemical Terminology The Gold Book. Oxford: Blackwell Science, 2nd edition.

Mori-Sánchez, P., Martín Pendás, A., \& Luaña, V. (2002). A classification of covalent, ionic, and metallic solids based on the electron density. J. Am. Chem. Soc., 124, 14721-14723.

Mulliken, R. S. (1928a). The assignment of quantum numbers for electrons in molecules. i. Phys. Rev., 32, 186-222.

Mulliken, R. S. (1928b). The assignment of quantum numbers for electrons in molecules. ii. correlation of molecular and atomic electron states. Phys. Rev., 32, 761-772. 
Nalewajski, R. F., Koster, A. M., \& Escalante, S. (2005). Electron localization function as information measure. J. Phys. Chem. A, 109(44), 1003810043.

Parr, R. G., Donnelly, R. A., Levy, M., \& Palke, W. E. (1978). Electronegativity: The density functional viewpoint. J. Chem. Phys., 68(8), 38013807.

Parr, R. G. \& Pearson, R. G. (1983). Absolute hardness: Companion parameter to absolute electronegativity. J. Am. Chem. Soc., 105, 7512-7516.

Pauli, W. (1925). über den einfluss der geschwindigkeitsabhängigkeit der elektronenmasse auf den zeemaneffekt. Z. Phys., 31, 373-385.

Pauling, L. (1948). The Nature of the Chemical Bond. Ithaca: Cornell University Press.

Pauling, L. (1954). Modern structural chemistry. Nobel Lecture.

Pilme, J. \& Piquemal, J.-P. (2008). Advancing beyond charge analysis using the electronic localization function: Chemically intuitive distribution of electrostatic moments. J. Comput. Chem., 29, 1440-1449.

Pitzer, K. S. (1946). Electron deficient molecules. i. the principles of hydroboron structures. J. Am. Chem. Soc., 67, 1126-1132.

Ponec, R. (1997). Electron pairing and chemical bonds. chemical structure, valences and structural similarities from the analysis of the fermi holes. $J$. Math. Chem., 21, 323-333.

Ponec, R. (1998). Electron pairing and chemical bonds. molecular structure from the analysis of pair densities and related quantities. J. Math. Chem., 23, 85-103.

Ponec, R., Cooper, D. L., \& Savin, A. (2008). Analytic models of domainaveraged fermi holes: A new tool for the study of the nature of chemical bonds. Chem. Eur. J., 14, 3338-3345.

Ponec, R. \& Duben, A. J. (1999). Electron pairing and chemical bonds: Bonding in hypervalent molecules from analysis of fermi holes. J. Comput. Chem., 20, 760-771.

Ponec, R. \& Roithova, J. (2001). Domain-averaged fermi holes-a new means of visualization of chemical bonds. bonding in hypervalent molecules. Theor. Chem. Acc., 105, 383-392. 
Popper, K. R. (1992). Quantum Theory and the Schism in Physics: From The Postscript to the Logic of Scientific Discovery. Oxon: Routledge.

Salem, L. (1978). Faithful couple: The electron pair. Journal of Chemical Education, 55(6), 344-348.

Salmon, W. (1984). Explanation and the causal structure of the world. Princeton, NJ: Princeton University Press.

Savin, A. (2005). On the significance of elf basins. J. Chem. Sci., 117, $473-475$.

Savin, A., Becke, A. D., Flad, J., Nesper, R., Preuss, H., \& von Schnering, H. G. (1991). A new look at electron localization. Angew. Chem. Int. Ed. Engl., 30, 409.

Savin, A., Jepsen, O., Flad, J., Andersen, O. K., Preuss, H., \& von Schnering, H. G. (1992). Electron localization in the solid-state structures of the elements: the diamond structure. Angew. Chem. Int. Ed. Engl., 31, 187190.

Savin, A., Nesper, R., Wengert, S., \& Fässler, T. F. (1997). Elf: The electron localization function. Angew. Chem. Int. Ed. Engl., 36, 1809-1832.

Savin, A., Silvi, B., \& Colonna, F. (1996). Topological analysis of the electron localization function applied to delocalized bonds. Can. J. Chem., 74, 1088-1096.

Scemama, A., Caffarel, M., \& Savin, A. (2007). Maximum probability domains from quantum monte carlo calculations. J. Comput. Chem., 28, 442.

Scemama, A., Chaquin, P., \& Caffarel, M. (2004). Electron pair localization function: A practical tool to visualize electron localization in molecules from quantum monte carlo data. J. Chem. Phys., 121, 1725-1735.

Scerri, E. R. (2000). Philosophy of chemistrys-a new interdisciplinary field? J. Chem. Educ., 77(4), 522.

Schmider, H. L. \& Becke, A. D. (2000). Chemical content of the kinetic energy density. J. Mol. Struct. (Theochem), 527, 51-61.

Shaik, S. S., Danovich, D., Silvi, B., Lauvergnat, D., \& Hiberty, P. (2005). Charge-shift bonding-a class of electron pair bonds emerges from valence bond theory and supported by electron localization function approach. Chem. Eur. J., 21, 6358-6371. 
Shannon, C. E. \& Weaver, W. (1949). The Mathematical Theory of Communication. Urbana: The University of Illinois Press.

Sidgwick, N. V. \& Powell, H. M. (1940). Bakerian lecture. stereochemical types and valency groups. Proc. Roy. Soc. A, 176, 153-180.

Silvi, B. (2002). The synaptic order: a key concept to understand multicenter bonding. J. Mol. Struct., 614, 3-10.

Silvi, B. (2003). The spin pair compositions as local indicators of the nature of the bonding. J. Phys. Chem. A, 107, 3081-3085.

Silvi, B. (2004). How topological partitions of the electron distributions reveal delocalization. Phys. Chem. Chem. Phys., 6, 256-260.

Silvi, B., Fourré, I., \& Alikhani, E. (2005). The topological analysis of the electron localization function : a key for a position space representation of chemical bonds. Monatshefte für Chemie, 136, 855-879.

Silvi, B. \& Gatti, C. (2000). Direct space representation of the metallic bond. J. Phys. Chem. A, 104, 947-953.

Silvi, B. \& Gillespie, R. (2007). The elf topological analysis contribution to conceptual chemistry and phenomenological models. In C. F. Matta \& R. J. Boyd (Eds.), The Quantum Theory of Atoms in Molecules: From Solid State to DNA and Drug Design (pp. 141-161). New York: John Wiley \& Sons Inc.

Silvi, B. \& Savin, A. (1994). Classification of chemical bonds based on topological analysis of electron localization function. Nature, 371, 683-686.

Strevens, M. (2004). The causal and unification approaches to explanation unified-causally. Nô̂s, 38, 154-176.

Strevens, M. (2006). Scientific explanation. In D. M. Borchert (Ed.), Encyclopedia of Philosophy. Detroit: Mcmillan Reference USA, 2nd edition.

Thom, R. (1993). Prédire n'est pas expliquer. Paris: Flammarion.

Thomson, J. J. (1904). On the structure of the atom: an investigation of the stability and periods of oscillation of a number of corpuscles arranged at equal intervals around the circumference of a circle; with application of the results to the theory of atomic structure. Phil. Mag., 7, 237-265. 
Tsirelson, V. \& Stash, A. (2002). Determination of the electron localization function from electron density. Chem. Phys. Lett., 351, 142-148.

Uhlenbeck, G. E. \& Goudsmit, S. (1925). Ersetzung der hypothese vom unmechanischen zwang durch eine forderung bezglich des inneren verhaltens jedes einzelnen elektrons. Naturwissenschaften, 13, 953-954.

Uhlenbeck, S. G. G. (1926). Spinning electrons and the structure of spectra. Nature, 117, 264-265.

van Brakel, J. (2003). The ignis fatuusa of reduction and unification. Annals of the New York Academy of Sciences, 988, 30-43.

van Brakel, J. (2006). Kant's legacy for the philosophy of chemistry. In D. Baird, E. Scerri, \& L. McIntyre (Eds.), Philosophy Of Chemistry, volume 242 of Boston Studies in the Philosophy of Science (pp. 69-91). Springer Netherlands.

Vasconi, P. (1999). Sistema delle scienze naturali e unitsà della conoscenza nell'ultimo Kant. Firenze: Leo S. Olschki.

von Weizsäcker, C. F. (1935). Zur theorie der kermassen. Z. Phys., 96, 431-458.

Wagner, F. R., Bezugly, V., Kohout, M., \& Grin, Y. (2007). Charge decomposition analysis of the electron localizability indicator: A bridge between the orbital and direct space representation of the chemical bond. Chem. Eur. J., 13, 5724-5741.

Woodward, J. (2011). Scientific explanation. In E. N. Zalta (Ed.), The Stanford Encyclopedia of Philosophy. Winter 2011 edition. 


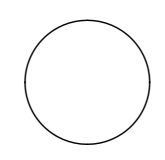

$$
c_{\pi}(\mathbf{r})=0
$$

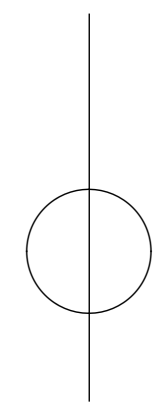

$$
c_{\pi}(\mathbf{r}) \propto 4 / \Omega^{2}
$$

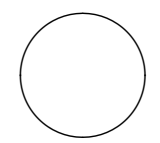

$c_{\pi}(\mathbf{r})=0$

Figure 1: Each half space contains two of opposite spin electrons and the density is assumed to be constant. The population $\bar{N}(\mathbf{r})$ of the sampling volume being denoted by $q$, the antiparallel pair population of the sample is also constant and equal to $\frac{q^{2}}{2}$. The spin pair composition is identically zero when the sample is entirely in the same half space, it reaches its maximum when the sample crosses the boundary. 


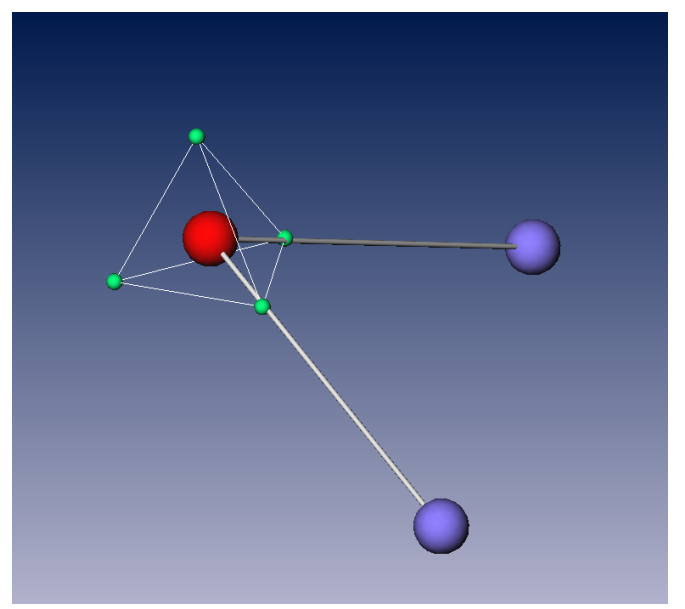

(a)

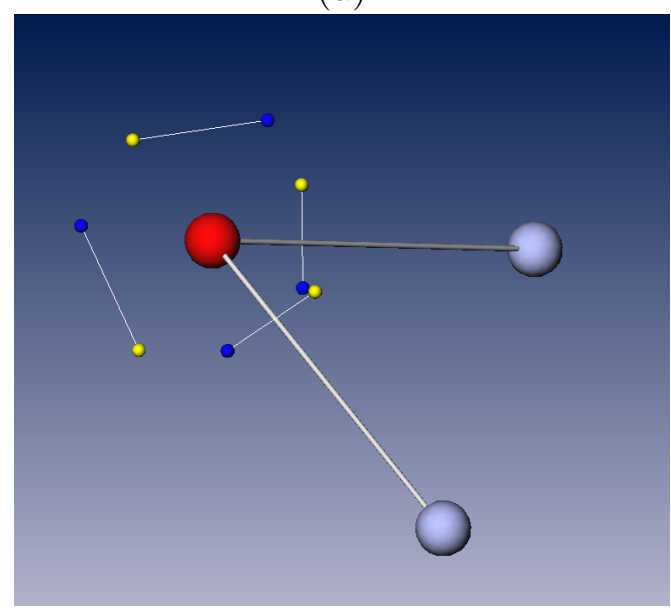

(c)

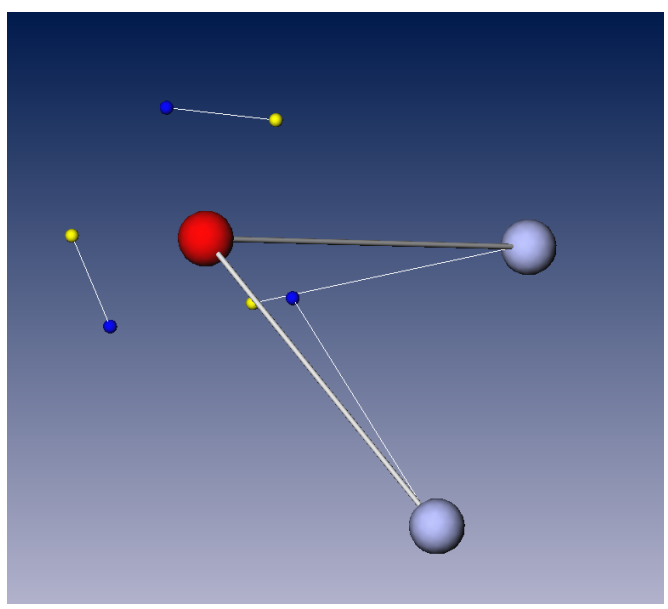

(b)

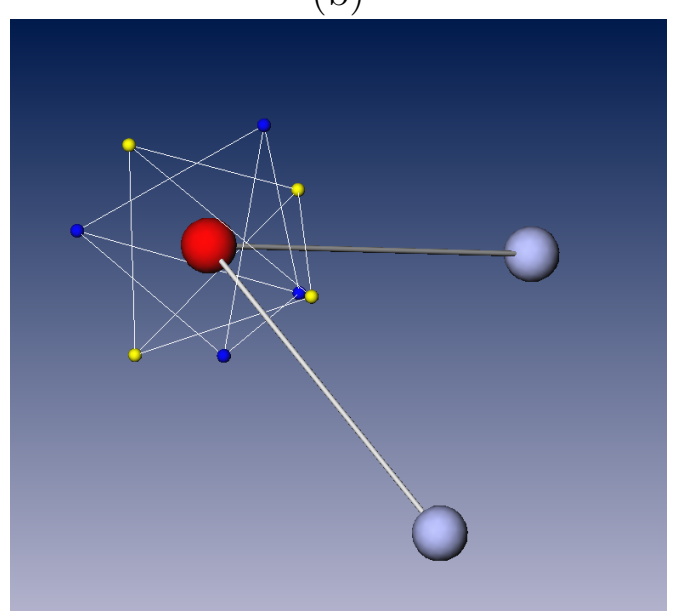

(d)

Figure 2: $\Gamma^{(N)}$ maxima electron positions in the water molecule. The spin coordinate is represented by two colors, yellow and blue. The oxygen atom kernel is represented by a red sphere, the hydrogen nucleus by a light blue sphere. (a) single determinant wave function, opposite spin electron, in green, positions coincide at the maximum, the white lines show the tetrahedral arrangement of the electron pairs, (b) Correlated VQMC wavefunction at a first maximum of $\Gamma^{(N)}$, the white lines link opposite spin points corresponding to pairs. (c) Correlated VQMC wavefunction at a second maximum. (d) same as (c) and the white lines link same spin positions showing the Linett's double quartet arrangement. From ref. (Scemama et al., 2007). 


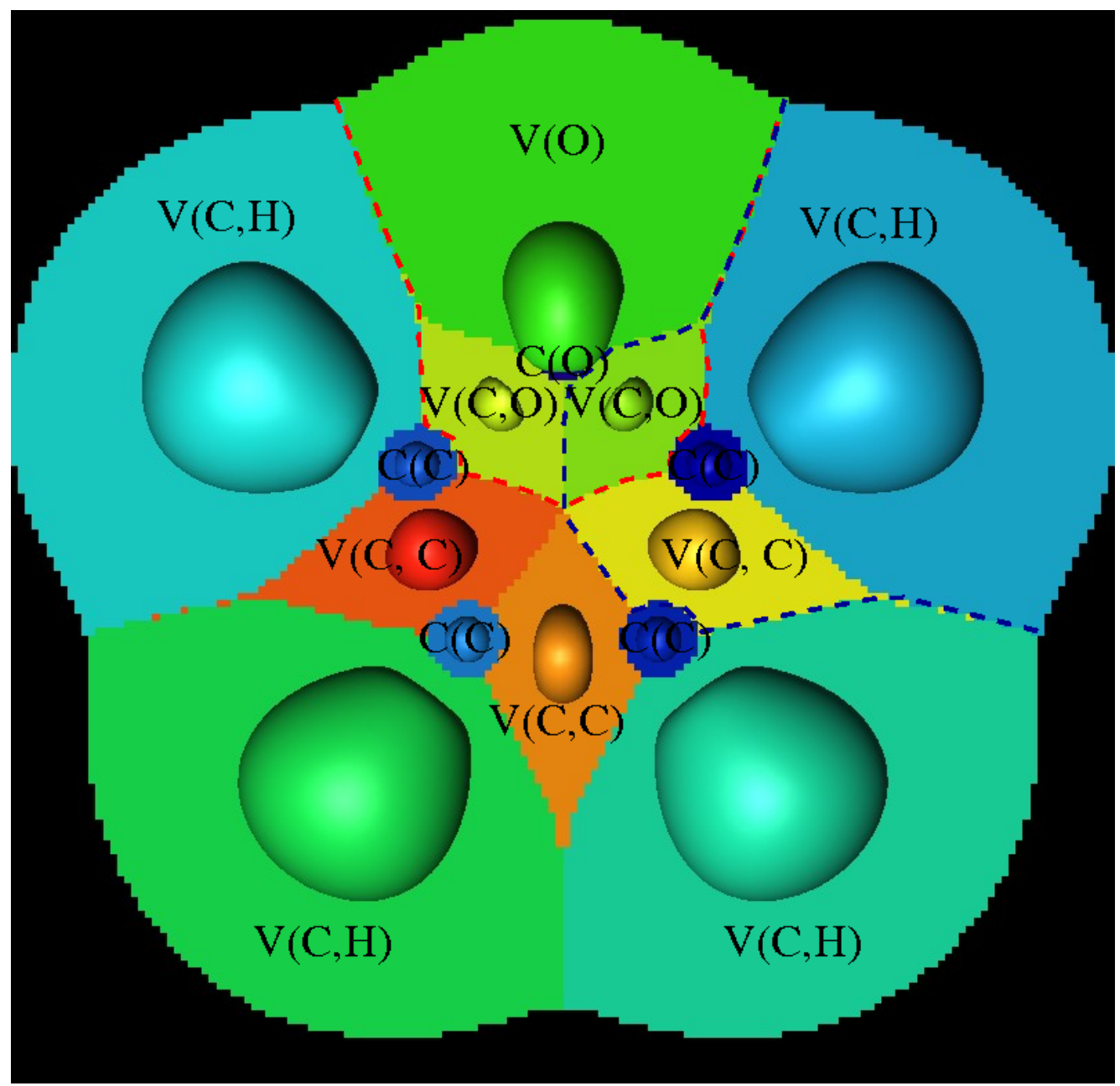

Figure 3: ELF basins of the furan molecule. The red and blue dotted lines delineate the oxygen and carbon valence shells 

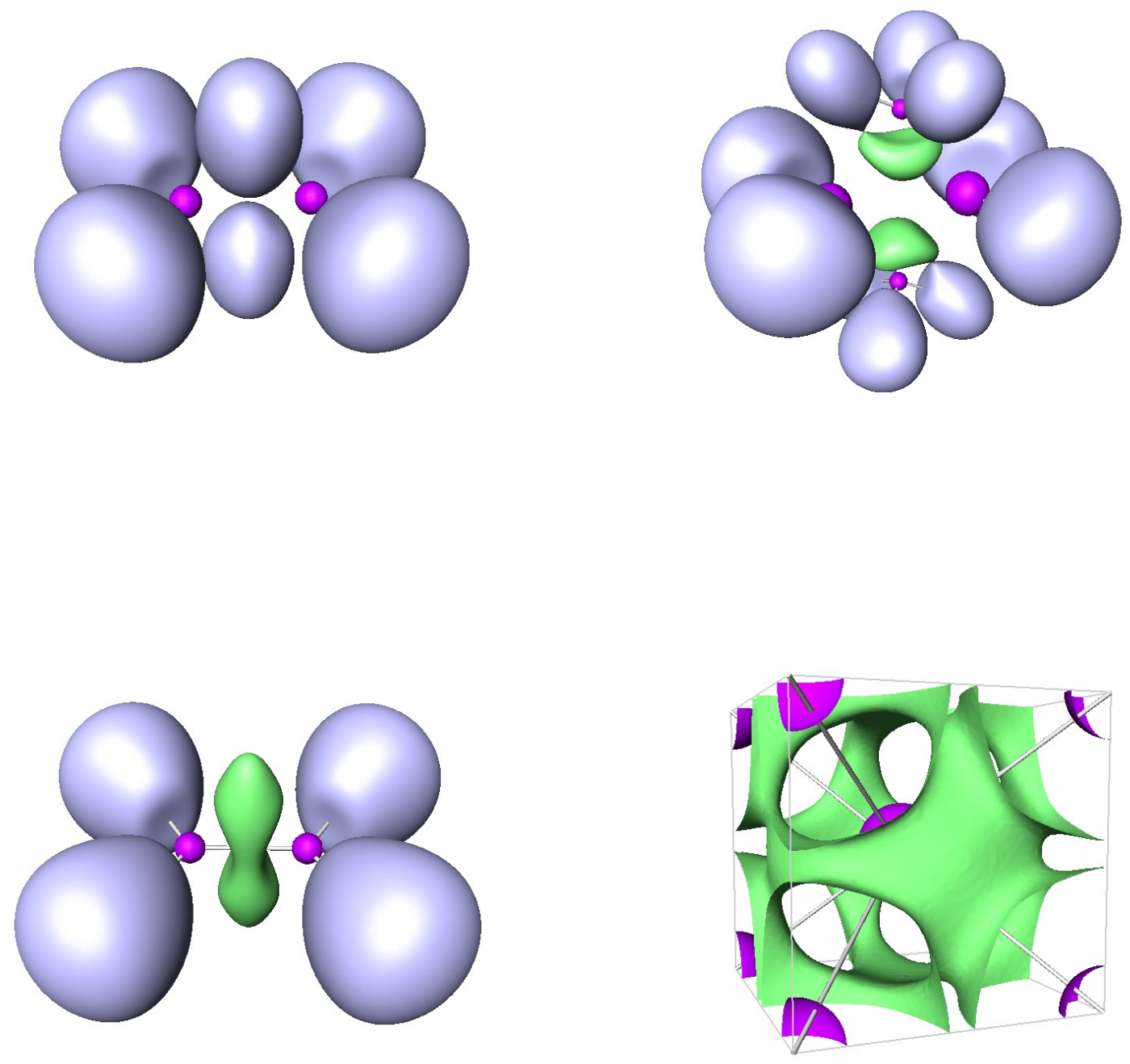

Figure 4: $\mathrm{ELF}=0.8$ isosurface for $\mathrm{B}_{2} \mathrm{H}_{6}, \mathrm{C}_{2} \mathrm{H}_{4}\left(\mathrm{AlCH}_{3}\right)_{2}$ and $\mathrm{C}_{2} \mathrm{H}_{4}, \mathrm{ELF}=0.5$ of the body centered cubic structure of lithium. 